\title{
Atypical Diabetic Ketoacidosis: Case Report
}

\author{
Hüseyin Demirci ${ }^{1}$, Ramazan Coşar $^{2}$, Özcan Çiftçi ${ }^{3}$, Iş̧lay Kalan Sar1 ${ }^{3}$ \\ 'Division of Endocrinology and Metabolic Disorders, Department of Internal Medicine, Turgut Özal University Faculty of Medicine, Ankara, Turkey \\ ${ }^{2}$ Department of Internal Medicine, Kırıkkale University Faculty of Medicine, Kırıkkale, Turkey \\ ${ }^{3}$ Division of Endocrinology and Metabolic Disorders, Department of Internal Medicine, Kırıkkale University Faculty of Medicine, Kırıkkale, Turkey
}

Background: Diabetic ketoacidosis (DKA) is a potentially life-threatening complication of diabetes mellitus and can lead to death if untreated. It is a complex metabolic state characterised by hyperglycaemia, acidosis and ketonuria. Bonsai is one of the herbal incense products that contains synthetic cannabinoid and can be easily accessible via the internet in many countries. It cannot be detected in blood and urine studies using conventional methods. Synthetic cannabinoid abuse is associated with severe side effects, including tachycardia, high blood pressure, acidosis, excess sedation and coma. Case Report: A 17-year-old male patient was brought to the emergency department with sudden onset of dyspnoea.
Laboratory investigations revealed hyperglycaemia, acidosis and ketonuria. He was admitted to the intensive care unit with a diagnosis of diabetic ketoacidosis. He was not considered a typical case of diabetic ketoacidosis because of the tendency to hypokalaemia, persistent tachycardia and bronchoscopic findings. We learned from his friends that he had used cannabis for a week and used bonzai on the day that he was brought to the emergency service.

Conclusion: Diabetic ketoacidosis with prolonged acidosis and tendency to hypokalaemia are investigated for the consumption of synthetic cannabinoids.

Keywords: Cannabinoids, diabetic ketoacidosis, hypokalaemia
Diabetic ketoacidosis (DKA) is an acute, major, life-threatening complication of diabetes mellitus. DKA results from severe insulin deficiency and mainly occurs in type 1 diabetes. DKA may be the first symptom of previously undiagnosed diabetes, but it may also occur in people known to have diabetes as a result of a variety of conditions such as infections, myocardial infarction, stroke, pancreatitis, trauma or poor compliance with insulin therapy. Vomiting, nausea, deep gasping breathing (Kussmaul respiration), pronounced thirst, abdominal pain, malaise, and generalised weakness are typical symptoms (1). Patients may also present with altered consciousness, disorientation, confusion or occasionally coma when the condition is severe (1).

Diabetic ketoacidosis is diagnosed with combination of hyperglycaemia, acidosis and ketonuria. The American Diabetes Association categorises DKA in adults into three stages of severity (Table 1) (1). Treatment includes correction of dehydration, hyperglycaemia, and electrolyte imbalances (1).
Synthetic cannabinoids were developed in the 1960s for clinical applications and research, but their therapeutic use was not approved by The Food and Drug Administration (FDA). However, over the past years, many herbal incense products such as bonzai (spice, dream, Jamaican blue, K2), which contain synthetic cannabinoids, are legally sold by head shops and on the internet in many countries. Affordability and easy accessibility via the internet contribute to the popularity of these drugs (2). Synthetic cannabinoids induce metabolic effects such as nausea and vomiting, hyperglycaemia, hypokalaemia and acidosis (3); however, they are undetectable in routine blood and urine drug screening methods $(4,5)$. Ingestion usually occurs via smoking and the consumption of synthetic cannabinoids, and is associated with severe adverse effects and life-threatening conditions, including tachycardia, agitation, high blood pressure, excess sedation, loss of

This report was presented as a poster at the $4^{\text {th }}$ National Diabetes Congress, 17-21 April 2013, Antalya, Turkey.

Address for Correspondence: Dr. Ramazan Coşar, Department of Internal Medicine, Kırıkkale University Faculty of Medicine, Kırıkkale, Turkey Phone: +90 5332850526 e-mail: ramazancosar@gmail.com

Received: 09.03.2014 Accepted: $30.10 .2014 \cdot$ DOI: 10.5152/balkanmedj.2015.15123

Available at www.balkanmedicaljournal.org

Cite this article as:

Demirci H, Coşar R, Çiftçi Ö, Sarı IK. Atypical diabetic ketoacidosis: case report.

Balkan Med J 2015;32:124-6. 
TABLE 1. Diagnostic criteria for DKA

\begin{tabular}{lccc}
\hline & $\begin{array}{c}\text { DKA } \\
\text { glucose level } \\
>250 \mathrm{mg} / \mathrm{dL})\end{array}$ & $\begin{array}{c}\text { Moderate (plasma } \\
\text { glucose level } \\
>250 \mathrm{mg} / \mathrm{dL})\end{array}$ & $\begin{array}{c}\text { Severe plasma } \\
\text { glucose level } \\
>250 \mathrm{mg} / \mathrm{dL})\end{array}$ \\
\hline $\begin{array}{l}\text { Arterial } \mathrm{pH} \\
\text { Serum bicarbonate } \\
(\mathrm{mEq} / \mathrm{L})\end{array}$ & $15.25-7.30$ & 7.00 to $>7.24$ & $<7.00$ \\
$\begin{array}{l}\text { Urine ketone } \\
\text { Serum ketone }\end{array}$ & Positive & 10 to $<15$ & $<10$ \\
$\begin{array}{l}\text { Effective serum } \\
\text { osmolality }\end{array}$ & Positive & Positive & Positive \\
Anion gap & $>10$ & Variable & $\begin{array}{c}\text { Positive } \\
\text { Variable }\end{array}$ \\
Mental status & Alert & Alert/drowsy & Stupor/coma \\
\hline
\end{tabular}

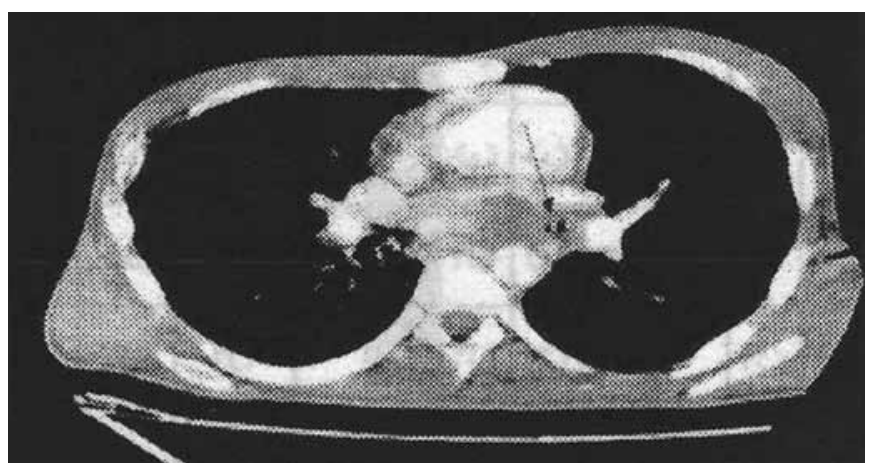

FIG. 1. Narrowing of the left main bronchus

consciousness and coma (6). We report here a 17 -year-old male patient with diabetic ketoacidosis after consumption of synthetic cannabinoids. Written informed consent was obtained from the patient's family.

\section{CASE PRESENTATION}

A 17-year-old male was admitted to the emergency department with sudden onset of dyspnoea. The report given by his relatives stated that the patient, who tended to fall asleep, had experienced a cough, weight loss and polydipsia for several weeks. There was no history of chronic disease or drug use. Clinical examination revealed a dehydrated male with a heart rate of 140 beats $/ \mathrm{min}$, temperature of $37^{\circ} \mathrm{C}$ and a blood pressure of 160/90 $\mathrm{mmHg}$. He was tachypnoeic and dyspnoeic with a respiratory rate of 28 breaths/minute. The patient's skin was hot and dry, pupils were isochoric and had no focal neurological deficit. Left lung sounds were decreased with diffuse rhonchi and the abdomen was soft and non-tender; bowel sounds were present in 2 of the 4 quadrants. Electrocardiogram (ECG) showed sinus tachycardia at a rate of 118 beats per minute. Laboratory investigation revealed a metabolic acidosis with arterial blood $\mathrm{pH}$ of 6.99 and bicarbonate of $4.1 \mathrm{mmol} / \mathrm{l}$. Arterial $\mathrm{pO}_{2}$ and $\mathrm{pCO}_{2}$ levels were $78 \mathrm{~mm} \mathrm{Hg}$ and $16 \mathrm{~mm} \mathrm{Hg}$, respectively. Plasma glucose was $392 \mathrm{mg} / \mathrm{dL}$ and 3+ ketones were present in the urine. Potassium was $3.4 \mathrm{mmol} / \mathrm{L}$, and liver and renal function tests were normal. Complete blood count showed an elevated white blood cell count of $31,300 \mathrm{~mm}^{3} / \mu \mathrm{L}$.

The patient was admitted to the intensive care unit with a diagnosis of diabetic ketoacidosis. Intravenous fluids, insulin and potassium replacement and empirical antibiotic treatment was started. Chest computed tomography (CT) was performed due to markedly decreased left lung sounds (Figure 1). Consolidation areas were detected in the posterior segment of the left upper lobe and posterobasal segment of the right lower lobe. Also, the left main bronchus was found to be narrowed at chest $\mathrm{CT}$ and bronchoscopy was performed. More pronounced on the left, bilateral oedema and haemorrhage were observed.

The patient was relieved after opening the narrowed bronchus. Bronchoscopic bronchoalveolar lavage culture was negative. The patient's fluid replacement, intravenous insulin, 20$40 \mathrm{mEq} / \mathrm{h}$ potassium and empirical antibiotic treatment was continued. The patient showed persistent hypokalaemia and deep acidosis. The patient was not considered a typical case of diabetic ketoacidosis because of the tendency to hypokalaemia, although an average of $20 \mathrm{mEq} / \mathrm{h}$ of potassium was given, with persistent tachycardia and bronchoscopic findings. His relatives were interviewed regarding the use of the toxic substance. It was learned from his friends that the patient had used cannabis for a week and used bonzai on the day that he was brought to the emergency service. Urine drug screens were negative and no blood alcohol was detected. Urine-specific laboratory analysis for cannabinoids metabolites could not performed in our laboratory and the consumption of synthetic cannabinoids could not be confirmed with laboratory analyses.

The patient was in respiratory distress again on the fourth day of admission and granulation tissue that nearly completely obstructed the lumen was found on the upper lobe of the left lung in bronchoscopy. The patient improved after the obstructed lumen was opened. Acidosis, hyperglycaemia and patient respiratory symptoms were improved and oral feeding was initiated on the sixth day of admission. Insulin doses were adjusted according to the patient's blood glucose monitoring and he was discharged. Glycaemic control was good and blood glucose levels were close to normal when he was referred to the policlinic three days after hospital discharge. The patient was admitted to the emergency department with massive haemoptysis one day after the policlinic visit and was not saved despite resuscitation.

\section{DISCUSSION}

Cannabinoids are divided into 3 groups: endocannabinoid, phytocannabinoid and synthetic cannabinoid. They act as 
TABLE 2. Adverse clinical effects reported with use of K2 products

\begin{tabular}{ll}
\hline & Seizures \\
& Agitation \\
& Irritation \\
Central Nervous System & Loss of Consciousness \\
& Anxiety \\
& Confusion \\
& Paranoia \\
& Fever \\
Autonomic & Mydriasis \\
& Tachycardia \\
Cardiovascular & Hypertension \\
& Chest Pain \\
Metabolic & Cardiac Ischemia \\
& Hypokalemia \\
Gastrointestinal & Hyperglycemia \\
Other & Nausea \\
& Vomiting \\
\end{tabular}

neuromodulators and have effects on motor learning, appetite, pain, emotions, synaptic transmission, memory, immune system, autonomic nervous system and microcirculation (7). Unlike endocannabinoids, synthetic cannabinoids are full agonists with increased potency $(3,6)$. They have a longer duration of action and their side effects are evident.

"Spice" and "K2" represent two of the more popular brand names that became widely available in the United States (3). Although these products are typically labelled as "incense" and "not for human consumption" or "for aromatherapy only", they are ingested by smoking (3). In many countries, they are easily accessible and marketed as reliable herbal products.

Severe and life-threatening symptoms may occur due to the consumption of synthetic cannabinoids (Table 2) (3). In the U.S., 11,000 patients per year consult the emergency services because of the side effects of synthetic cannabinoids (6). Synthetic cannabinoids cannot easily be detected in urine and blood studies using conventional methods (6).

Clinical case reports regarding acute intoxication of synthetic cannabinoids describe a variety of somatic and neuropsychiatric effects like nausea and vomiting, tachycardia, hypertension, hypokalaemia, hyperglycaemia, convulsions, agitation, hallucination, and acute psychosis $(8,9)$. Similarly, our patient had tachycardia, hyperglycaemia, hypertension and hypokalaemia.

Loschner reported a patient with hypoxaemia and haemoptysis after the inhalation of a synthetic cannabinoid and diagnosed diffuse alveolar haemorrhage revealed with bronchoscopy (10). Also, our patient had hypoxaemia and bilateral oedema, with haemorrhage observed on bronchoscopy.

Hermanns-Clausen and his friends reported four cases of acutely intoxicated patients after the consumption of synthetic cannabinoids. They observed a wide spectrum of symptoms including mild hyperglycaemia, hypokalaemia and tachycardia (2). They detected the synthetic cannabinoid metabolites of JWH-018 and JWH-073 by urine laboratory analysis. We could not confirm exposure to synthetic cannabinoids by urine laboratory analysis for cannabinoid metabolites.

Synthetic cannabinoids cannot be detected in the urine and blood using conventional methods and sometimes induce serious side effects. It is recommended that patients with diabetic ketoacidosis with prolonged acidosis and a tendency to hypokalaemia are investigated for the consumption of synthetic cannabinoids.

\section{Ethics Committee Approval: N/A.}

Informed Consent: Writen informed consent was obtained from the patient's parents for the publication of this case report and any accompanying images.

Peer-review: Externally peer-reviewed.

Author contributions: Concept - H.D., Ö.Ç.; Design - H.D.; Supervision - H.D., Ö.Ç.; Resource - H.D., R.C.; Materials - Ö.Ç., I.K.S.; Data Collection\&/or Processing - H.D., R.C., I.K.S.; Analysis\&/or Interpretation - H.D., I.K.S., R.C.; Literature Search - R.C., I.K.S.; Writing - R.C., I.K.S.; Critical Reviews - H.D., Ö.Ç., R.C., I.K.S.

Conflict of Interest: No conflict of interest was declared by the authors.

Financial Disclosure: The authors declared that this study has received no financial support.

\section{REFERENCES}

1. Kitabchi AE, Umpierrez GE, Miles JM, Fisher JN. Hyperglycemic crises in adult patients with diabetes. Diabetes Care 2009;32:1335-43. [CrossRef]

2. Hermanns-Clausen M, Kneisel S, Hutter M, Szabo B, Auwarter V. Acute intoxication by synthetic cannabinoids - Four case reports. Drug Test Anal 2013;5:790-4. [CrossRef]

3. Seely KA, Prather PL, James LP, Moran JH. Marijuana-based drugs: innovative therapeutics or designer drugs of abuse? Mol Interv 2011;11:36-51. [CrossRef]

4. Beuck S, Möller I, Thomas A, Klose A, Schlörer N, Schanzer $\mathrm{W}$, et al. Structure characterisation of urinary metabolites of the cannabimimetic JWH-018 using chemically synthesised reference material for the support of LC-MS/MS-based drug testing. Anal Bioanal Chem 2011;401:493-505. [CrossRef]

5. Hudson S, Ramsey J. The emergence and analysis of synthetic cannabinoids. Drug Test Anal 2011;3:466-78. [CrossRef]

6. Fattore L, Fratta W. Beyond THC: the new generation of cannabinoid designer drugs. Front Behav Neurosci 2011;5:60. [CrossRef]

7. Rodriguez de Fonseca F, Del Arco I, Bermudez-Silva FJ, Bilbao A, Cippitelli A, Navarro M. The endocannabinoid system: physiology and pharmacology. Alcohol Alcohol 2005;40:2-14. [CrossRef]

8. Forrester MB, Kleinschmidt K, Schwarz E, Young A. Synthetic cannabinoid exposures reported to Texas poison centers. $J A d$ dict Dis 2011;30:351-8. [CrossRef]

9. Simmons J, Cookman L, Kang C, Skinner C. Three cases of "spice" exposure. Clinical Toxicol (Phila) 2011;49:431-3. [CrossRef]

10. Loschner A, Cihla A, Jalali F, Ghamande S. Diffuse alveolar hemorrhage: add "greenhouse effect" to the growing list. CHEST Journal 2011;140:149A. [Cross Ref] 